\title{
Desenvolvimento e relacões de trabalho na fumicultura sul-brasileira
}

RONALDO GUEDES DE LIMA*

\section{Introdução}

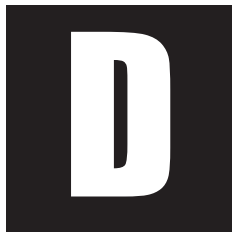

esde os primeiros contatos com a literatura sociológica da formação familiar de agricultura, interessou-me discutir os elementos deste tema, elencando, em particular, as distintas posições teóricas de autoridades nacionais, com relação ao trabalho desenvolvido pelos cultivadores de fumo do sul do Brasil, na forma de integração vertical.

Vários autores vêem na agricultura familiar contemporânea, uma categoria genérica ante a diversidade de situações específicas e particulares presentes nas estruturas agrárias universais (Wanderley, 2001; Sacco dos Anjos, 2003). Há estudos recentes que questionam o uso do termo "agricultura familiar", devido ao decréscimo de sua importância na produção agrícola global, por um lado e ao nascimento de outras formas ou sistemas produtivos (modernos) como se constata na França, através do surgimento da agricultura individual, ou mesmo, da chamada agricultura de grupo, por outro (Jegouzo, apud Sacco dos Anjos, 2003). Muito embora toda a organização econômica-política e espacial tenha sido construída, ao longo da história, a partir da dicotomia urbano-rural, (...) en una relación de dominación

\footnotetext{
* Engenheiro Agrônomo, Doutorando em Agronomia na Faculdade de Agronomia Eliseu Maciel da Universidade Federal de Pelotas. Brasil
} 
y explotación económica del campo por la ciudad (Hervieu, 1996, p. 37), o mundo rural atual continua detendo especificidade e, ao mesmo tempo, interdependência.

Ao longo do processo histórico capitalista dos países centrais, não só se desmistificou o mito (marxista-leninista) da dissolução da agricultura familiar em favor do caráter capitalista de uma determinada agricultura, como cada vez mais, hoje em dia, os espaços rurais constituem-se em locais não somente de produção. O mundo agrícola (...) comienza a descubrir no el fin de la familia, sino la emergencia de una pluralidad de modelos de organización familiar (Hervieu, 1996, p. 73), nos quais se verificaria um processo de ruptura entre empresa (unidade produtiva) e tradição familiar (unidade familiar). Neves (1995) reconhece que a unidade familiar convive com outras lógicas e princípios sociais de troca. Os membros da família podem incorporar preferências em torno de outras demandas, por vezes mais compatíveis do que a histórica produção agrícola. Como outros, essa autora admite a diversidade de formas de economia familiar na agricultura e propõe (...) que as unidades de produção sejam pensadas muito mais como expressões das posições ocupadas pelos agricultores, como valorização de determinadas opções ou alternativas (...) (Neves, 1995, p. 34).

A consolidação da unidade de produção familiar e da recente emergência do trabalho agrícola individual é uma criação da Economia e da sociedade moderna, diz Servolin, apud Jean (1994). Ambas, exploração familiar e individual, souberam, no curso do desenvolvimento da Economia moderna, responder satisfatoriamente às expectativas da sociedade, através da produção de alimentos baratos e em quantidade segura. Pelo menos dois fatores contrários à tese marxista-leninista, isto é, a defesa da manutenção da propriedade familiar, na contemporaneidade, são assinalados por Jean (1994): o papel do Estado como definidor de políticas agrícolas e agrárias e a incorporação das inovações técnicas no processo produtivo. 
Como em outros países, nos EUA, a agricultura familiar teve capacidade histórica de empreender dinamismo tecnológico em seu processo; a base familiar integrou-se aos mercados, de modo a gerar volumes de vendas consideráveis, seja sem a contratação, seja com a contratação de serviço extrafamiliar (Abramovay, 1998). Assim como nos países capitalistas centrais, aqui no Brasil (destaque aos estados do Sul), desenvolve-se também uma forma de agricultura familiar dinâmica, cujo peso econômico é muito significativo, sendo, portanto, descabido associar a noção de agricultura familiar com a pequena produção, ou agricultura camponesa (Abramovay, 1998; 1997).

Porém o próprio autor observa que, ao lado do segmento familiar dinâmico, desenvolvem-se milhões de unidades consideradas precárias, pequenas e com baixas rendas, em países com forte tradição latifundiária como a nação brasileira. Se, nos países centrais, a agricultura familiar moderna configura-se como o segmento principal (número de explorações existentes), nas economias em desenvolvimento há estruturas agrícolas contrastantes entre si, desde aquelas explorações comprometidas com o desenvolvimento de uma agricultura pouco dependente de inputs e voltada à sustentação social de seus agentes, até segmentos diretamente integrados aos mercados agrícolas que objetivam a valorização de seus ativos (Sacco dos Anjos, 2003).

Enquanto Abramovay (1998) explica a predominância de unidades de explorações familiares pelo maior peso do comportamento dinâmico dos agricultores nos mercados concorridos da agricultura, outros, como Wanderley (2001) destacam a preservação de traços culturais de formas de agricultura anterior, no mundo rural de hoje. Particularmente nas sociedades em vias de desenvolvimento, conservam-se expressivos tipos de agricultores com traços básicos de campesinato, nos termos do que trata a literatura (Sacco dos Anjos, 2003). 
Para Abramovay (1997), o dinamismo da agricultura familiar contemporânea não depende de características supostamente "culturais" dos agricultores, mas de três fatores básicos: 1) a base material com que produzem (área, fertilidade das terras); 2) a formação dos agricultores, e 3) o ambiente socioeconômico em que atuam (mercados, crédito, informação, assistência técnica, escola, saúde, etc.). Outros, porém, propõem que se analise a formação familiar da agricultura, levando em conta também o fator sociocultural (Lamarche, 1993; Wanderley, 2001). A noção contrária àquela evocada por Abramovay, aparece refletida na seguinte afirmação de Wanderley (2001): "o campesinato não se restringe à economia de subsistência". Segundo essa autora, tanto no passado quanto no presente, os camponeses lutam por mercados para suas mercadorias. Ou seja, sempre foi objetivo desses agricultores ter acesso a atividades estáveis e rentáveis. O duplo propósito de integrar-se ao mercado e garantir autoconsumo (...) é fundamental para a constituição do (...) patrimônio sociocultural do campesinato brasileiro (Wanderley, 2001, p. 42).

Sendo a agricultura familiar nosso objeto de estudo, destacamos duas importantes contribuições orientadoras, que definem as bases essenciais da forma familiar. Primeiro, Lamarche (1993, p. 15), apresenta um esquema de análise em que a exploração familiar corresponde a uma unidade de produção agrícola onde propriedade e trabalho estão intimamente ligados à família. Segundo, Gasson e Errington, apud Abramovay (1997, p. 74) destacam-se seis características da agricultura familiar: 1) a gestão é feita pelos proprietários; 2) os responsáveis pelo empreendimento estão ligados entre si por laços de parentesco; 3) o trabalho é fundamentalmente familiar; 4) o capital pertence à família; 5) o patrimônio e os ativos são objeto de transferência intergeracional no interior da família e 6) os membros da família vivem na unidade produtiva.

As características citadas, contudo, não conformam um modelo idealizado e geral. Fundamentalmente elas orientam a compreensão teórica a 
respeito da diversidade de formas de agricultura familiar. Como bem observa Abramovay (1997), é freqüente, por exemplo, os membros da família não residirem na unidade de produção. Pode acontecer também que o processo sucessório envolva indivíduos que não são do grupo familiar e que nem todos os membros da unidade familiar se envolvam com o trabalho agrícola, tendência esta documentada nos países capitalistas centrais.

Sem a pretensão de eleger este ou aquele pressuposto teórico como verdadeiro e absoluto, ao admitir que as distintas elaborações teóricas podem entrecruzar-se, seguimos os pressupostos sociológicos de Max Weber, por entender que sua obra apresenta considerações importantes atinentes à organização do trabalho familiar agrícola, bastante úteis à análise contemporânea que versa sobre a dinâmica produtiva agrária local. Nestes, o autor afasta-se da noção determinista e da concepção exclusivamente materialista da História e elabora o que se chamou de teoria da causalidade. Assim, a perspectiva weberiana fundamenta-se na 'indeterminação' (no caráter de probabilidade) do devir histórico. Além disso, para Weber, além do econômico outros elementos da realidade, sejam políticos ou culturais (crenças, valores) têm um papel central no desenvolvimento das sociedades modernas (Weber, apud Aron, 2003; Giddens, 1995). Nesse sentido, torna-se possível compreender a conduta econômica de um grupo social, numa conjuntura determinada, através de motivações extra-econômicas ou da visão de mundo deste.

A base da reflexão teórico-metodológica empregada por Weber (1991) consiste na compreensão interpretativa da ação social (comportamento humano) orientada por um sentido visado. Weber distingue quatro tipos de ação: 1) ação racional referente a fins; 2) ação racional referente a valores (crença, dignidade, dever, moral); 3) ação afetiva (estado emocional); e 4) ação tradicional (costume, hábitos cotidianos). É fato raro, no entanto, uma ação social orientar-se exclusivamente por uma dessas quatro maneiras. 
Estes tipos de orientação, segundo Weber (1991), não representam uma classificação completa de todos os modos de orientação possíveis, no entanto eles são conceitualmente puros, criados para fins sociológicos. Este recurso metodológico da sociologia compreensiva serve à construção da noção do "tipo ideal" weberiano. O conceito de tipo ideal (...) está associado ao que é característico da sociedade e da ciência moderna, a saber, o processo de racionalização (Aron, 2003, p. 756).

No arcabouço analítico de Weber, a ação tem o caráter subjetivo. Os motivos, meios e fins das ações sociais passam pelas concepções ou visão de mundo dos agentes envolvidos nas ações. Embora o traço característico do mundo moderno seja a racionalização orientada pelos fins, a realidade social capitalista não se desenvolve exclusivamente aos mecanismos econômicos. Em certos aspectos do desenvolvimento da sociedade moderna, encontra-se o impacto da ciência e da burocracia (Weber, apud Giddens, 1995).

Nas categorias sociológicas que tratam da gestão econômica, Weber aponta dois tipos de racionalidade na economia de troca: gestão patrimonial e gestão aquisitiva. Na primeira, a ação é orientada à satisfação de necessidades próprias como os bens materiais e os imateriais. A ação economicamente orientada pode servir como meio de obtenção de outros resultados. Diferentemente de uma economia baseada no cálculo de capital, a gestão patrimonial familiar pode, além da provisão de seu orçamento básico, desprender-se desta, transformando-se numa economia de troca regular para fins de aquisição. Neste caso, os proprietários de seus meios de produção (obtenção) usam as fontes de renda geradas, empregando-as, por exemplo, num empreendimento aquisitivo sem cálculo capitalista. No segundo tipo de gestão, a ação é orientada pelas oportunidades de ganhar, seja de uma só vez, seja repetidamente, novos poderes de disposição sobre bens, isto é, uma atividade aquisitiva de caráter capitalista com poderes de disposição sobre dinheiro. Esta feição racionalista extrema do cálculo de capital pressu- 
põe, conforme Weber (1991), a luta entre os homens no mercado, uns contra os outros.

Vale lembrar, porém, que de modo algum, essas duas racionalidades abrangem a totalidade da gestão econômica. De acordo com Weber (1991), a ação econômica pode realizar-se por sentido alheio ao cálculo. Neste caso, pode haver influência relativamente importante da ação tradicional (ou condicionada por fatores afetivos) sobre a forma racional econômica. Dito de outra forma, o desenvolvimento da gestão econômica racional (...) está condicionada também, em considerável grau, por ações e acontecimentos não-econômicos e não-cotidianos (...) (Weber, 1991, p. 41).

Embasado nesses pressupostos, passo a discutir a particularidade da produção fumícola no sul do Brasil, focando inicialmente a gênese e o desenvolvimento dessa atividade produtiva, no Rio Grande do Sul.

\section{Gênese e desenvolvimento da fumicultura no Rio Grande do Sul}

A maioria, se não todas as produções acadêmicas voltadas à produção de fumo, apontam o estado gaúcho, precisamente a região de Santa Cruz do Sul, como o espaço geográfico onde a economia do fumo concentrou seu crescimento. Foi neste município que os primeiros colonizadores vindos da Alemanha em 1849 iniciaram suas atividades agrárias, movidas por força de trabalho essencialmente familiar.

No inicio da colonização, os imigrantes organizaram uma economia de subsistência quase absoluta, incluindo a produção de fumo em corda e em folha. Tanto os alimentos como os utensílios básicos e as vestimentas eram produzidos por eles próprios. O consumo de mercadorias externas ao estabelecimento agrícola limitava-se, segundo Cunha (1991), ao sal, ao café, 
ao ferro (na forma de ferramentas) e algum tecido, usualmente adquiridos em casas de negócios, chamadas pelos imigrantes de "vendas".

Os primeiros cultivos realizados na colônia de Santa Cruz pelos imigrantes resultaram do conhecimento próprio deles, herdado do solo pátrio, no Velho Continente. No princípio, despontaram as lavouras de

batata inglesa, abóboras, aveia, centeio, ervilha, trigo e rábanos para a alimentação, fumo para uso próprio, colza para fabricar óleo para a iluminação e linho para a confecção de tecidos, produtos (...) cujas sementes, não raro, foram trazidas consigo da Alemanha (Kirchhoff, apud Cunha, 1991, p. 134).

Contando com o apoio do governo provincial ligado à administração da colônia (instrução e recebimento gratuito de sementes, inclusive de fumo), os imigrantes, aos poucos, foram introduzindo outros produtos locais como: milho, feijão, arroz, amendoim, batata doce e mandioca para a alimentação e o algodão para fabricar tecidos (Kirchhoff, apud Cunha, loc. cit).

Essas atividades agrícolas conjugadas à criação de animais (de trabalho e de consumo) fizeram das unidades familiares o necessário para que elas pudessem subsistir ao tempo, produzindo primeiramente para o autoconsumo e comercializando eventuais excedentes. As sobras da produção agrária eram trocadas nas casas comerciais da nova povoação de Santa Cruz e nas casas das linhas coloniais que iam surgindo, por mercadorias não produzidas na unidade doméstica. No princípio da colonização, as transações nunca envolviam moeda, mas se concretizavam à vista.

A prática de trocas comerciais sem dinheiro, realizada nos primeiros anos da povoação, permitia aos comerciantes (vendistas) acumular mercadorias que, primeiramente, eram levadas em carroças ou caravanas de burros até Rio Pardo. De lá, por via fluvial, o fumo prensado chegava principalmente em Porto Alegre. Da capital gaúcha, o produto era transportado em navios para a Alemanha e países do Prata. 
A partir de 1857, Porto Alegre vai constituir-se, segundo Singer, apud Montali (1979, p.35), no centro comercial de toda a região colonial. Para ela converge (...) a produção agrícola das colônias e a partir dela são distribuídos os produtos importados para as mesmas.

Durante os dez primeiros anos, a colônia de Santa Cruz consolida-se, e, em 1859 sua povoação é elevada à categoria de freguesia (Menezes, apud Montali, 1979, p.28). Nesse ano, de acordo com Relatórios dos Presidentes da Província de São Pedro do Rio Grande do Sul, citados por Cunha (1991), a população da colônia já registrava 2.723 habitantes.

Em decorrência de novas ocupações e da necessidade de os imigrantes começarem a saldar as dívidas coloniais, ${ }^{1}$ novas áreas de cultivos foram abertas. Por conta disso, cresceu aos poucos a produção primária e o artesanato.

Na fase seguinte, entre 1860 e 1881, a produção para a subsistência persiste, mas, segundo Cunha (1991), o colono cada vez mais intensifica a produção para o mercado local. Por causa desta demanda, o fumo, assim como outras mercadorias, vão tendo destaque quantitativamente na colônia. Com base nos Relatórios dos Presidentes da Província de São Pedro do Rio Grande do Sul, Vogt (1997) destaca o crescimento em mais de 9.000\% do volume de fumo produzido entre os anos de 1858 e 1866, que somou, respectivamente, 287 e 25.858 arrobas.

Esse último montante, convertido em dinheiro, desbancou o feijão e o milho como principais cultivos de subsistência e de comércio na colônia. ${ }^{2}$

\footnotetext{
1 De acordo com Cunha (1991), o crescimento da produção e exportação de fumo em Santa Cruz se deveu, entre outros fatores, à necessidade de pagamento das dívidas coloniais dos novos imigrantes chegados a partir de 1854. Outros meios também foram colocados pela administração colonial para estimular a produção de fumo, como: 1) o melhoramento das vias de transporte e comunicação e o conseqüente estímulo ao desenvolvimento do comércio, e 2) a distribuição de sementes selecionadas e a divulgação de informações técnicas sobre o cultivo de tabaco.

2 Cf. nota registrado por Vogt (1997, p. 75 - 76), a partir de depoimento do presidente da Província do Estado do Rio Grande do Sul, Francisco Ignácio M. Homem de Mello, em sessão realizada em 1867 na Assembléia Legislativa da Província.
} 
Ano após ano, o fumo ia crescendo em importância comercial, tornando-se dominante na ponta de produtos exportados pela colônia, resultado da intervenção combinada da administração colonial e do capital no processo produtivo que na fase seguinte do desenvolvimento econômico de Santa Cruz determinará a especialização da sua produção (Cunha, 1991, p.162).

A especialização da produção de fumo em folha em Santa Cruz, segundo consta, aconteceu a partir da safra 1865/66, diz Vogt (1997). Tanto Vogt quanto Cunha, parecem assumir o caráter da especialização da produção fumícola, devido ao favorecimento das transações locais, bem antes da chegada do capital estrangeiro à região. No entanto outros autores como Etges (1991) e Montali (1979), opõem-se à versão da especialização. Pelo menos até o ano de 1918, não se verifica especialização entre os estabelecimentos, pois todos cultivavam mercadorias tanto para a subsistência como para o mercado (Montali, 1979). Montali só vai admitir a especialização dentro das unidades agrícolas, quando se iniciou o processo de subordinação da propriedade agrária não-capitalista à indústria capitalista de beneficiamento de fumo. Em outras palavras, quando o truste anglo-americano British American Tobacco, pôs em prática o sistema integrado de produção de fumo na região.

Já Etges (1991, p. 35) afirma (...) que não existe a monocultura do fumo na região. Existem, segundo ela, pequenas explorações produtoras de fumo que são a maioria na região, ao mesmo tempo que existem outras unidades onde o fumo não é cultivado.

A solidificação do mercado na colônia e, depois, no município de Santa $\mathrm{Cruz}^{3}$ deveu-se historicamente à acumulação de capitais pelos vendistas que se apropriaram de grande parte do sobretrabalho gerado pela mão-de-obra familiar do colono (Vogt, 1997, p. 93). Conforme Maurício Schuck,

3 Conforme a Fundação de Economia e Estatística, apud Vogt (1997), o município de Santa Cruz do Sul foi criado em março de 1877. O novo município desmembrou-se de Rio Pardo. 
Eram eles [os comerciantes] que monopolizavam as informações relativas aos preços, o que permitia a manipulação e a especulação em seu favor. Eram os comerciantes, na maioria das vezes, os detentores dos meios de escoamento da produção para os postos de venda e portos fluviais (...). Isto possibilitava aos negociantes o arrebanho, a título de custo de frete, de boa parte do preço final das mercadorias (Schuck, apud Vogt, loc. cit.).

Além das trocas comerciais já referenciadas anteriormente e dos serviços de transportes prestados, o comerciante também desempenhava a função de banqueiro. (...) emprestava dinheiro mediante a cobrança de juros e recebia depósitos sem remunerar o capital, não sendo raros os casos em que cobrava emolumentos para guardar o dinheiro dos colonos (Vogt, 1997, p. 94). Segundo esse autor, o comerciante também exercia o papel de líder comunitário. A casa comercial (...) era um misto de residência, posto de trocas, local de beneficiamento da produção, botequim e ponto de reunião, era lá que os colonos acabavam tendo contato com assuntos os mais variados (Vogt, loc cit.).

Acumulando a função de agente financeiro, transportador e líder, o comerciante apropriou-se de grande parte do trabalho gerado nas unidades familiares de exploração de fumo. Nas palavras de Montali (1979, p. 36), o comerciante (...) se apropria de parcela do excedente dos produtores agrícolas não apenas nas trocas entre mercadorias agrícolas e manufaturadas, mas também através de taxas cobradas pelo transporte dos produtos para outras localidades.

Porém, nem todas as casas comerciais tiveram recursos econômicos para transacionar o fumo, ou seja, adquirir do colono, beneficiar e vendê-lo adiante. Aqueles residentes nas picadas ou nas linhas trabalhavam como representantes de comerciantes mais fortes, os transformadores de matéria-prima. Estes, em melhores condições de localização (no núcleo munici- 
pal) negociavam juntamente com o fumo diversas mercadorias ausentes nas unidades familiares. Desta forma alguns comerciantes, detendo o monopólio mercantil, garantiram a acumulação de capitais. Daí em diante, brotariam as pré-condições, para a dominação capitalista da produção (Vogt, 1997).

Antes mesmo da chegada da primeira transnacional ligada ao beneficiamento de fumo in natura, Santa Cruz integra-se definitivamente à divisão inter-regional do trabalho, através do comércio de alguns poucos produtos agropecuários, sendo destaque o fumo (em folha e em corda), com participação nas exportações, na ordem de 59\%, em 1881; de 39\%, em 1895, e de 57\%, em 1899 (Meneses, apud Montali, 1979, p. 32).

Com a crescente integração da agricultura local à economia nacional e estrangeira em particular pelo bom desempenho produtivo do fumo, emerge no município santa-cruzense, um incipiente processo de industrialização. Todavia outros fatos contribuíram para alavancar o desenvolvimento industrial no município: intenso processo de acumulação de capitais nas mãos de alguns comerciantes monopolizadores das transações locais e a melhoria infraestrutural das rodovias, ferrovias e comunicações entre o município e a capital gaúcha. Em síntese, a industrialização em Santa Cruz deveu-se inicialmente, (...) ao sucesso de sua agricultura, voltada para a exportação (...) (Montali, 1979, p. 47), permitindo, de um lado, estimular o desenvolvimento das agroindustrias de beneficiamento e, de outro, pela disponibilidade de capital local nas mãos dos comerciantes, iniciando com isso, a instalação de novas unidades fabris mais bem aparelhadas tecnologicamente.

\section{Ampliação e domínio agroindustrial sobre a produção}

A partir de 1917, as unidades artesanais e manufatureiras da agricultura vão alterar seu processo produtivo, por conta dos investimentos industriais realizados, especialmente naquelas com finalidades de beneficiamento 
e industrialização do fumo. Nessa época, havia seis estabelecimentos no município, voltados à preparação do fumo para exportação e à fabricação de cigarros (Borba, apud Montali, 1979). O uso do cigarro se constituiria, no decorrer da guerra e nos anos subseqüentes, num produto preferido pelos consumidores que, até então, enrolavam o fumo desfiado em palha.

O avanço do comércio cigarreiro determinou a entrada no Brasil, em 1914, da British American Tobacco (BAT), quando esta comprou a fábrica manufatureira de cigarros de Albino Souza Cruz, no Rio de Janeiro.

Três anos depois, a empresa com o nome de Brazilian Tobacco Corporation, instala-se em Santa Cruz do Sul. O empreendimento foi bancado pelo truste anglo-americano BAT que, desde 1914, detinha o controle acionário da empresa Souza Cruz. Até 1962, o seu antigo proprietário manteve-se na presidência da empresa.

Com a vinda deste capital estrangeiro, fortalece-se a expansão do cultivo de fumo apropriado à fabricação de cigarros. A partir da chegada da BAT, tratou-se de induzir mais os agricultores a continuarem plantando fumos claros, preferencialmente com novas espécies, bem mais adequadas à industrialização de cigarros. Com isso, o que se visava era o abastecimento da fábrica no Rio de Janeiro (...) e a possibilidade de obtenção de tipos de fumos até então não cultivados no país (Vogt, 1997, p. 102).

Um marco deste processo ocorreu em 1918, quando a BAT, de maneira experimental, introduziu os fumos curados artificialmente em fornos (ou estufas). As novas técnicas de cultivo e pré-beneficiamento das folhas foram trazidas dos Estados Unidos por técnicos, especialmente contratados pela empresa. ${ }^{4}$ Seu campo preferencial de atuação foi o Rio Grande do Sul,

4 Um dos técnicos requisitados pela BAT, em 1928, foi o professor americano Richard Tankersley. Nessa época, o técnico desembarcou em solo santa-cruzense para difundir entre os agricultores da região as novas técnicas de cultivo voltado à produção de fumos Virgínia, espécie considerada ideal à fabricação de cigarros (Jornal Gazeta do Sul, 12/12/96, p. 58). 
especificamente em Santa Cruz que, à época, já era uma região tradicionalmente produtora de fumo em folha. ${ }^{5}$

Ainda em 1918 inaugura-se uma nova relação entre agricultor e capital. ${ }^{6}$ Nasce o sistema integrado de produção de fumo, levado a cabo pela Cia. Brasileira de Fumo em Folha a qual instala, em 1920 a primeira usina de beneficiamento de fumo em Santa Cruz. Os primórdios da nova relação que surge são contados por Ludwig da seguinte forma:

O cultivo racional do fumo em Santa Cruz do Sul foi introduzido pela Companhia Brasileira de Fumo em FoIha que aqui se estabeleceu, após ter estudado, profundamente, o nosso solo e a nossa gente; aqui construiu, logo de início, enormes armazéns; aqui empregou jovens santa-cruzenses em seus escritórios e outros departamentos; percorrendo os seus técnicos o município analisando as terras, ensinando o colono o plantio racional do tabaco, recomendando-Ihe a construção de fornos para secar fumos de estufa; visitando-os, periodicamente, observando as suas plantações, continuando a assistir e, assim, até a colheita, garantindo eles, a colocação do produto (Ludwig, apud Vogt, 1997, p. 103 - 104).

5 Além da Souza Cruz, surgem novas unidades industriais dedicadas ao beneficiamento do fumo e à fabricação de cigarros. $\mathrm{O}$ caráter industrial altera qualitativamente os produtos exportados. $\mathrm{O}$ fumo expedido de Santa Cruz até 1919, exceto uma pequena parcela, era não-beneficiado (in natura) (Montali, 1979, p. 55). A partir da atuação em moldes capitalistas, as empresas agregaram qualidade em seus produtos, fruto dos investimentos tecnológicos em curso.

6 Embora se tenha discutido antes o domínio mercantil do fumo por comerciantes locais, Vogt (1997) delimita, dois momentos ou etapas de subordinação do colono/fumicultor perante o capital. A primeira forma de subordinação compreenderia o período de 1850 - 1916. Neste período, o vínculo mercadológico do fumo com os vendistas das localidades (comerciantes) solidificaria a acumulação de capital pela classe mercantil da época. Por decorrência, são criadas as pré-condições predominantemente capitalistas. Com a chegada da transnacional, alastra-se, a partir de 1917, uma outra relação de dominação e de estreito vínculo com o mercado. É o que Vogt (1997) denomina de subordinação ao capital industrial. 
De lá para cá, o sistema integrado tem-se mostrado tão enrijecido que vem desencadeando, entre as autoridades das Ciências Agrárias, discussões acaloradas sobre o tipo de relação social estabelecida entre agroindústria e agricultor. Antes, porém, de adentrarmos nos aspectos produtivos atuais da fumicultura sul-brasileira, convidamos o leitor a rememorar a discussão acerca das distintas noções teóricas, voltadas às relações de produção desse ramo agrícola.

\section{Interpretações teóricas sobre as relações de produção na fumicultura}

Enquanto uns trabalham a noção teórica de natureza capitalista, reconhecendo no agricultor traços que o identificam como proletário, outros seguem orientações distintas para compreender o processo social de reprodução dos agricultores fumeiros. No marco do primeiro grupo ou vertente, temos os que seguem a noção teórica de Maria de Nazareth B. Wanderley, autora da obra intitulada "O camponês: um trabalhador para o capital", cujo referencial se baseia na literatura de clássicos marxistas como K. Kautsky e V. Lênin.

Para o caso brasileiro, a reprodução do trabalho familiar na agricultura não se efetua exclusivamente pela proletarização do agricultor. Sob o manto da produção capitalista, tanto os pequenos proprietários quanto os nãoproprietários (assalariados, parceiros, arrendatários e posseiros) ocupam um espaço criado pelo próprio capital, mas na condição de trabalhadores para o capital. Ainda assim, apesar de proprietários jurídicos da terra e de outros meios produtivos e mesmo sendo dirigentes da produção, não são senhores de seu sobretrabalho, nem conseguem escapar à ameaça real de proletarização (Wanderley, 1985, p. 74). Na produção vertical, o nível de organização interna do trabalho familiar parece contaminar-se por objetos 
de um poder de decisão que, cada vez mais, sofre influência externa do grande capital. Esse sistema tem como principal característica (...) o fato de que o capital industrial evita o investimento na aquisição da propriedade da terra e controla "do exterior" a produção da matéria prima agrícola que necessita para a transformação industrial (Wanderley, 1985, p. 68). Uma outra característica desse sistema é a especialização da produção. Para Wanderley (1985), o trabalho familiar tende a somar esforços naqueles produtos que oferecem mais vantagens de preços no mercado, até mesmo interferindo nas práticas de autoconsumo, mas sem anulá-las.

Acrescentemos, para discussão, a concepção teórica graziana cujo veio leninista se assemelha às alusões de Wanderley. Conforme cita Graziano da Silva (1982), tanto no processo de tecnificação da unidade produtiva como no assalariamento puro do agricultor, há subordinação de trabalho ao capital. Para esse autor, a recriação da pequena produção brasileira consiste na conversão do antigo camponês em um trabalhador para o capital, ou seja, em um "novo camponês", que (...) não se apropria necessariamente do lucro, nem da renda da terra, como condição da produção, (...). O grande capital retira-lhe esse excedente, permitindo que ele se aproprie apenas do necessário à sua reprodução como pequeno produtor (Graziano da Silva, 1982, p. 138). Esse novo camponês, ainda que conserve parcial ou formalmente a propriedade direta dos meios de produção e que organize o trabaIho com base na mão-de-obra familiar, segue submetido ao processo de proletarização, isto é, o camponês se "descampesiniza", converte-se em um trabalhador para o capital (Graziano da Silva, 1982).

Alguns atores seguem essas orientações marxista-leninistas, com algumas variações interpretativas, tais como: Vogt (1997), Cunha (1991) e Liedke (1977). Vogt entende que a pequena produção agrícola de fumo na região de Santa Cruz nunca foi autônoma, independente e auto-suficiente. Apesar disso, dentro da unidade de produção, as relações de produção não são 
essencialmente capitalistas. Embora, para o autor, esses agricultores familiares não constituam uma categoria homogênea, ele reconhece que esse grupo começa a passar por um processo de maior diferenciação socioeconômica por causa dos novos processos tecnológicos de produtividade e qualidade exigidos no setor. Os estabelecimentos limitados pelo tamanho físico, conjugados aos que se situam em áreas íngremes, terão dificuldades de incorporar progresso técnico, por conseqüência, (...) provavelmente serão excluídos do sistema integrado da produção de tabaco (Vogt, 1997, p. 254) e, assim, constituirão uma classe semiproletária de pequenos agricultores que viverão da combinação da agricultura de subsistência com o assalariamento temporário nas cidades ou no meio rural.

Guardados os aspectos conjunturais da época especialmente na primeira metade da década de 90 (século XX) em que se anunciava uma superprodução mundial, com possíveis reflexos na queda da produção nacional, hoje a fumicultura mostra-se bastante competitiva no comércio exterior, provocando a ampliação no número de unidades de explorações integradas. Além disso, de modo recorrente, em amplas zonas do Brasil meridional, vemos o desenvolvimento de processos produtivos apoiados na utilização de equipamentos simples, desde o uso de tração animal até a cura e secagem do fumo em estufas convencionais ou semi-automáticas de ar forçado. Assim, constatamos que o prognóstico aventado por Vogt, até o momento não foi confirmado. Só uma drástica redução nos volumes produzidos internamente pode encetar um processo de seleção de agricultores mais aptos ou a exclusão daqueles com escassos recursos produtivos.

Embora Vogt e Cunha não reconheçam o assalariamento (disfarçado) no processo de reprodução da mão-de-obra familiar, eles constatam a extração e a apropriação do sobretrabalho gerado na unidade de exploração pelo capital agroindustrial em nível da circulação da mercadoria produzida pelos membros familiares. 
Contudo, enquanto Vogt (1997) aposta na inevitabilidade do processo de diferenciação social a partir do progresso técnico levado a cabo pelo sistema capitalista, ${ }^{7}$ Cunha (1991) atém-se ao pressuposto da especialização da produção, para quem o processo de acumulação agroindustrial capitalista se acentua mediante a progressiva especialização do trabalho naquela mercadoria que oferece melhores condições de comércio.

Com base em nossa percepção experiencial, podemos afirmar que, no seio das unidades agrícolas, há ainda hoje o desenvolvimento de outras atividades de autoconsumo paralelamente à condução da lavoura de fumo. Todavia não ignoramos a diminuição de trabalho e da produção voltados às práticas paralelas. Na maioria, não se avista a nulidade destas. Há até posições contrárias que argumentam inexistir a monocultura fumageira na região de Santa Cruz (Etges, 1991). Outros, preferem jogar com noções intermediárias, aludindo a que há (...) um certo grau de especialização na produção de fumo (...) (Liedke, 1977, p. 67), que serve de matéria-prima às agroindústrias.

Um terceiro trabalho de vertente marxista é apresentado por Liedke (1977). A autora, parte do pressuposto (...) de que o processo de dominação e de expansão do capitalismo na agricultura não implica necessariamente na sua homogeneização, ou seja, no desaparecimento de relações de produção não tipicamente capitalista (Liedke, 1977, p. 18). Para essa autora, a reprodução social do segmento da pequena agricultura, acontece pela subordinação ao modo de produção capitalista. No caso em questão, (...)

\footnotetext{
7 Há uma abordagem teórica diferente que mostra a agricultura familiar melhor adaptada para responder às exigências e às demandas da sociedade moderna, não sendo, portanto, uma forma social anacrônica da evolução histórica, mas um produto do próprio desenvolvimento da economia agrícola moderna. Em outras palavras, a agricultura familiar foi capaz de integrar rapidamente as inovações técnicas e produzir competitivamente a preços baixos e em quantidade suficiente hoje, considerados os excedentes no contexto da União Européia, devido à superprodução (Jean, 1994). Lá, porém, o Estado mostrou-se parceiro da classe agricultora, formulando políticas de crédito e de acesso à terra, com dispositivos jurídicos de regulação da economia agropecuária.
} 
trata-se de um processo de dominação do capital sobre a produção agrícola, através de um processo de concentração vertical, em que o setor industrial, controlando a produção e comercialização do fumo, determina os níveis de remuneração dos camponeses, segundo as suas necessidades e acumulação (Liedke, 1977, p. 19).

Necessidades essas, suficientes para atender a subsistência familiar e a reprodução do estabelecimento. Por esta via, Liedke, ao fazer referência a Samir Amin, contradiz a tese da obtenção do lucro médio e da existência de renda fundiária por parte dos pequenos agricultores. Entende-se assim, que a produção gerada pelos agricultores deve suportar níveis baixos de preços, propostos pelas agroindústrias. Mesmo se apropriando do sobretrabalho familiar, a agroindústria, bem como o processo geral de acumulação capitalista na agricultura não enveredam para uma proletarização franca dos camponeses. Na fumicultura, trata-se, sim, de uma relação social diferente, (...) de um modo específico de subordinação da força de trabaIho camponesa ao capital industrial (Liedke, 1977, p. 22). Fundamentalmente o capital intervém na unidade de produção agrícola de fumo (sem alterar a estrutura fundiária), mas neutralizando sua autonomia, tornando o agricultor apenas um "proprietário formal" da terra e dos meios de produção, diz Liedke.

Diferentemente das idéias marxista-leninistas e de seus seguidores supracitados, encontramos uma segunda noção defendida por autoridades nacionais. Paulilo (1990) refuta a noção de propriedade formal. Segundo ela, a entrada da lavoura fumícola no sul catarinense na forma de pacote, na década de 50 (século XX) não significou uma mudança de atividade (de ramo) dentro das pequenas explorações. Na época (1983), um estudo empírico concluiu: a lavoura fumícola é uma atividade a mais, e a monocultura não é nem praticada nem desejada pelos agricultores que ela entrevistou. Para Paulilo, é difícil aceitar os integrados como proprietários formais ou 
empregados das empresas integradoras, já que os próprios agricultores achamse fregueses e não integrados daquelas.

Uma segunda elaboração teórica oposta à linha marxista foi aventada por Montali (1979). Ela parte do referencial que aborda a coexistência de relações não-capitalistas e capitalistas no segmento agrário e no segmento industrial, como processo necessário para o desenvolvimento e acumulação do capitalismo.

Montali define os estabelecimentos agrícolas de fumo como sendo não-capitalistas e produtores simples de mercadorias. Embora a agroindústria subordine a unidade agrícola porque extrai o excedente produzido sob a égide de relações não capitalistas, o agricultor independente continua como proprietário dos meios de produção, mantendo o controle do processo de trabalho. Trabalho este, auxiliado por membros familiares que se envolvem em todas as etapas do processo de produção, da administração à execução.

Conforme Montali (1979, p. 143), na exploração familiar a finalidade última da produção agrícola não-capitalista é a sua subsistência, ou, sua reprodução, a qual é garantida, por uma parte, pelo recurso ao autoconsumo e, por outra, pelo mecanismo de crédito viabilizado pela agroindústria. Para a autora, o crédito constitui o mecanismo fundamental para a reprodução subordinada dos estabelecimentos agrícolas de fumo.

Semelhante pressuposto como esse defendido por Montali encontrase no estudo de Etges (1991). Esta autora, apoiada nas idéias de autores brasileiros como José de Souza Martins e Ariovaldo Umbelino de Oliveira, segue a vertente (...) que afirma que o campesinato, é uma classe social, que é criado e recriado na lógica contraditória do desenvolvimento capitalista (Etges, 1991, p. 34). Logo, defende que haveria a preservação de formas não-capitalistas na agricultura. Na fumicultura especificamente, o processo geraria formas não-capitalistas, não pela via da sujeição formal do trabalho agrário, mas pela sujeição da renda da terra ao capital monopolista. 
Isso dito, parece-nos inconsistente insistir na tese da proletarização como destino do agricultor integrado. A nossa vivência prática, conjugada à literatura consultada, aponta para o entendimento da especificidade da agricultura familiar e do processo agrícola do fumo, desenvolvido em pequenas áreas (média de 2,6 hectares) das propriedades, na forma de integração vertical. Ainda que a agroindústria fomente incessantemente a produtividade, competitividade e progresso técnico na produção agrícola, o trabalho interno no estabelecimento é basicamente dirigido por familiares, com rara racionalidade empresarial de maximização do lucro. Em outros termos, a unidade de exploração é movida pela informalidade administrativa e por certa autonomia da maioria dos processos. Lembrando os fundamentos sociológicos de M. Weber (1991), nesse caso em que há oportunidades de troca, trata-se de uma ação social típica que se orienta por "situações de interesses" (grifos do autor) em que a gestão patrimonial funciona como meio para atender às necessidades próprias e como fontes de renda.

O fumicultor, portanto, não se enquadra na condição de empresário familiar como querem Payés \& Silveira (1997). Esses autores, além de confundirem o conceito acerca do debate contemporâneo da agricultura familiar, estreitam a discussão, restringindo-a a suposta razão produtivista do agricultor familiar. Nesta visão controversa, sinalizam que os agricultores procuram obter "lucro", da mesma forma que os produtores capitalistas, a fim de valorizar o patrimônio, a melhoria do bem-estar familiar, via alocação de recursos e de trabalho, bem como a produção de mercadoria que aponte lucros mais vantajosos, a título de grandeza e risco (Payés \& Silveira, 1997). O equívoco dessa visão se desfaz quando partimos para a profunda compreensão da realidade concreta desses agricultores.

Na fumicultura, o trabalho e os meios materiais de produção, em vez de se organizarem pela razão do cálculo aquisitivo capitalista, requisitam longas jornadas que avançam à noite, em pelo menos 3 a 4 meses do ciclo 
anual da cultura, período em que culminam a colheita, cura e secagem das folhas.

A auto-exploração do trabalho foi um dos aspectos que Chayanov (1974) estudou, no princípio do século XX, sobre a organização da unidade econômica campesina russa em cujo núcleo teórico, residia o chamado balanço entre trabalho e consumo familiar como detonador dos processos de produção.

Mesmo naquele contexto específico (agrário russo), a contribuição chayanoviana, nos dias de hoje, auxilia, em parte, a compreensão das práticas cotidianas desenvolvidas pelos agentes da agricultura familiar. Porém uns consideram ser esta uma ferramenta analítica incapaz para explicar a totalidade expressa pelos agricultores. De fato, nem o marco chayanovista, leninista, kautskysta nem a corrente estruturalista representada por Shanin e Tepicht, dão conta por inteiro, para a análise explicativa do processo evidenciado hoje, das formas organizativas vivenciadas pelas explorações familiares (Tedesco, 1994). Há, sim, flexibilidade e redefinição constantes na pequena unidade familiar em face do desenvolvimento e da acumulação capitalista. A sua permanência, mesmo diante do progresso técnico de ponta, imprime em certas situações, dinamismo e seletividade. ${ }^{8}$

Os conflitos e as contradições resultantes das relações sociais (entre trabalho familiar e capital agroindustrial) constituem (...) um processo em constante reconstrução, o qual tem, na produção da mercadoria (excedente) e na lógica do movimento de valorização do capital, seu sentido de ser (Tedesco, 1994, p. 114 - 115).

8 Aqui o autor faz referência ao processo de seleção dos integrados que produzem aves e suínos. Ver TEDESCO, João C. Contratualização e racionalidade familiar. In: (Org.) Agricultura familiar: realidades e perspectivas. 3. ed. Passo fundo: UPF, 2001, p. $107-148$. 
O estabelecimento agrícola familiar hoje não pode ser visto apenas como funcional para a agroindústria (Tedesco, 2001; Paulilo, 1990). Por motivos diversos, associados à unidade de produção, redefinições internas convertem simultaneamente o sistema de integração em estratégia consciente de reprodução e sobrevivência familiar, bem como em mecanismo de alocação de trabalho em práticas diversificadas de subsistência (Tedesco, 2001).

Tal pressuposto aparece refletido nos depoimentos de fumicultores, que expressam a permanência no ramo da integração, devido principalmente à segurança que o sistema oferece pela aquisição total do produto, além do que, presentemente, são poucas outras alternativas produtivas para a maioria dos agricultores integrados.

Desde os primórdios em que o fumo ultrapassou em valor comercial as demais mercadorias da antiga colônia de Santa Cruz (1866), ${ }^{9}$ parece que os projetos que orientam as relações da família, voltam-se para objetivar a seguinte estratégia de reprodução social: manter a atividade mercantil com a soma do autoconsumo. Tal premissa nos é iluminada pela noção de "patrimônio sociocultural" de que cada agricultor e sua família dispõem, de um lado, e das escolhas políticas que lhes dizem respeito, efetuadas pela sociedade global, por outro (Lamarche, 1993). Em outros termos, segundo o mesmo autor, trata-se da dinâmica de funcionamento da unidade familiar embasada em dois domínios estratégicos: a memória que guardam de sua história (peso da tradição) e as ambições que têm para o futuro.

9 Cf. nota, registrado por Vogt (1997, p. 75 - 76), a partir de depoimento do presidente da Província do Estado do Rio Grande do Sul, Francisco Ignácio M. Homem de Mello, em sessão realizada em 1867 na Assembléia Legislativa da Província. 


\section{Quadro contemporâneo da fumicultura e estratégias familiares}

A evolução sócio-histórica da fumicultura rio-grandense concentrouse na região de Santa Cruz do Sul onde as condições eram favoráveis ao desenvolvimento da atividade, a saber: 1) a existência de uma estrutura fundiária baseada em pequenas propriedades; 2) a mão-de-obra disponível e afeita ao labor da cultura; e 3) uma infra-estrutura básica de produção e comércio.

Outra situação de favorecimento regional foi o embargo econômico imposto pela ONU à Rodésia (Zimbawe) em meados da década de 60 (século XX), na época, o maior fornecedor de fumos nobres da Europa. Esse acontecimento possibilitou ao sul do Brasil, crescer substancialmente no volume exportado.

A crescente demanda de fumo em folha no comércio estrangeiro, em face da aludida situação da Rodésia, levou corporações multinacionais a se instalarem em Santa Cruz. Já, no início dos 70, por conta da política interna de fomento aos investimentos estrangeiros e à exportação, ocorreu o processo de desnacionalização das empresas locais. Seguiu-se, com isso, um aumento da produção via adoção de inovações, tanto no âmbito das agroindústrias de processamento como na organização das unidades agrárias de produção, com a introdução sistemática das técnicas baseadas nos pacotes tecnológicos apoiados no modelo agroquímico.

Aos poucos, a técnica de melhoramento vegetal foi-se aprimorando e introduziu novas cultivares de fumo, vindo a assumir, nos dias de hoje, posição de destaque no cenário da fumicultura sul-brasileira. A boa performance das variedades Virgínia fez com que estas substituíssem o tipo Amarelinho, passando a representar, assim, a maior parcela de fumo plantado em solo brasileiro, mormente nos estados sulinos (RS, SC e PR), onde 
foi registrado um total geral superior a 400 mil hectares (ha) cultivados na recente safra, ${ }^{10}$ plantados por quase 200 mil agricultores.

Os atuais níveis de produtividade alcançados nas lavouras se devem, sobretudo, à introdução de inovações tecnológicas no processo produtivo desta solanácea, primeiramente, com o advento das inovações químicas e biológicas e, depois, na década de 90 (século XX), com as inovações agronômicas ${ }^{11}$ voltadas à preservação das áreas de plantio de fumo.

Em face desta questão, cabe a assertiva de Graziano da Silva, para quem

(...) as inovações biológicas, através das quais o homem interfere sobre as determinações das forças da natureza, visando a acelerá-las ou a transformá-las de modo a romper as barreiras que se antepõem ao capital (...). O ponto crucial das inovações biológicas é que elas colocam a natureza a serviço do capital, possibilitando a transformação da agricultura num ramo da indústria (Graziano da Silva, 1999, p. 45 - 46).

Em outra publicação, Graziano da Silva (1996), discute este processo de transformação da agricultura brasileira, como sendo o da industrialização da agricultura. Embora o conceito de industrialização da agricultura se encaixe na corrente marxista-leninista, ele mesmo admite a impossibilidade

10 A área plantada na safra 2003/04, aumentou quase 11 \% em relação á anterior, indicando uma estimativa recorde de 850 mil toneladas de produção (Jornal Gazeta do Sul, 14 e 15/02/04). Com essa produção, o Brasil continuará ostentando a posição de segundo maior produtor e primeiro exportador de fumo no mundo, por conta da qualidade da matéria-prima e do preço competitivo no mercado estrangeiro. No ano de 2004, a exportação de fumo em folha contabilizou US $\$ 1.380$ milhões, atrás da soja, carnes, café e açúcar, produtos de maior peso comercial, respectivamente (SECEX/MDIC, apud www.agricultura.gov.br).

11 São novos procedimentos, métodos e práticas culturais que visam a organização da produção através de recursos disponíveis, sem o aporte de novos produtos e/ou insumos (Graziano da Silva, 1999). No caso específico, trata-se, por exemplo, do cultivo mínimo, do plantio direto e do plantio escalonado de fumo. 
absoluta de domínio capitalista no campo. O progresso técnico na agricultura assume um caráter "incrustado", devido às características específicas deste setor, a saber: o papel da propriedade privada da terra e a interação entre o processo de produção com as forças da natureza (Graziano da Silva, 1999).

Nem mesmo a política de padronização do cultivo fumícola trouxe mudanças às relações sociais de produção, no interior da unidade. Os agricultores permaneceram proprietários dos seus meios de produção e dirigentes das tarefas agrárias, porém agora subordinados ao capital agroindustrial. Se antes eles estavam atrelados aos comerciantes da colônia, com a vinda da transnacional mudam as técnicas de produzir, enquanto a essência das relações de produção permanece inalteradas.

Além das poucas alternativas produtivas antes mencionadas, os agricultores plantadores de fumo sentem-se atraídos pelo mecanismo do sistema integrado que lhes oferece: 1) garantia de compra da produção; 2) transporte da produção sem ônus para o fumicultor; 3) crédito $^{12}$ de financiamento para a lavoura, investimentos e, não raro, adiantamento em dinheiro; 4) seguro mútuo da AFUBRA (Associação dos Fumicultores do Brasil) contra intempéries e queima de estufas e 5) assistência técnica gratuita. Soma-se a isso, o fator cultural fortemente enraizado na região tradicional rio-grandense, produtora dessa solanácea (Lima, 2000).

12 Até o surgimento do Sistema Nacional de Crédito Rural, implantado em meados dos anos 60, as agroindústrias, por conta própria financiavam as lavouras e os investimentos. Conveniadas com o Banco do Brasil (depois com os demais bancos), as empresas beneficiadoras, até hoje intermedeiam toda a operação creditícia. Elas são responsáveis por toda a documentação necessária e avalizam as operações de crédito. Assim, como no passado (década de 70), quando existiam os fartos recursos subvencionados, recentemente, com o PRONAF (Programa Nacional de Fortalecimento da Agricultura Familiar), o setor tabaqueiro mais uma vez soube usufruir desses benefícios. De todo o montante do programa nacional, a fumicultura sul-brasileira abocanhou, 15,7 \%, em 1997 e 15,0 \%, em 1998 (www.pronaf.gov.br). Cifras importantes, por tratar-se de uma atividade não-alimentar, sendo para alguns, um setor não-estratégico, em face dos objetivos de soberania. Por causa da mobilização de setores representativos da agricultura familiar, o Estado deixou de financiar a lavoura de fumo com recursos do PRONAF. Desde 2001, o banco financia a produção no campo, através da modalidade MCR6-2 (recursos próprios), com juros de 8,75 \% ao ano. 
Conforme aponta a AFUBRA (2004), cada propriedade planta em média 2,6 hectares de fumo, destacando-se, porém, em termos de área plantada, o cultivo de milho que, junto às demais atividades agrícolas paralelamente desenvolvidas no interior das unidades, mantém, segundo a ótica de muitos, o importante meio de vida das unidades familiares. O caráter diversificado da produção voltada ao autoconsumo, com venda do excedente é, provavelmente, a forma de as unidades familiares poderem resistir às pressões de preços baixos pagos às mercadorias produzidas. No caso em questão, sempre foi política das agroindústrias firmarem a importância da diversificação ao lado do fumo. A combinação de atividades do autoconsumo (vendendo as sobras), com a produção comercial (a lavoura de fumo) (...)é uma estratégia do capital para o rebaixamento dos custos monetários da produção (Vogt, 1997, p. 164), na medida em que a mão-de-obra representa cerca de $50 \%$ da planilha de cálculo do custo operacional de produção do fumo. ${ }^{13}$

Graziano da Silva (1999, p. 152) afirma que a produção complementar de outros produtos serve de sustento da família, porque (...) quando ocorre a subordinação da pequena produção à agroindústria, o produto principal mostra-se deficitário em termos de rendimento líquido.

Para outros, a diversificação, incluindo o produto da integração como aves e fumo, serve de promoção e segurança da integridade dos núcleos familiares. Os produtos da diversificação servem também para uma maior capacidade de reprodução da família integrada (Tedesco, 2001, p. 144),

\footnotetext{
13 Na obra de José de Souza Martins, o mesmo faz referência à produção familiar, como posicionada em uma situação de maior integração no mercado. Caso típico da produção fumageira. Conforme esse autor, os agricultores familiares, de acordo com sua lógica original, tendem a produzir diretamente produtos que se destinam ao consumo diário dos familiares. No entanto, quando se mergulha na produção mercantil, diminuindo a produção direta dos meios de vida, o agricultor se torna especializado e "... mergulha também nas incertezas e nos mistérios do mercado, expressões de uma vontade que não é a sua" (Martins, 2002, p. 78).
} 
(...) o que, caso contrário, implicaria uma remuneração melhor para a matéria-prima produzida.

Diante do que foi exposto pelas autoridades e segundo nossa atuação prática com esse segmento produtivo da agricultura (a produção integrada de fumo), nos inclinamos mais, sem maniqueísmo, a identificar os pressupostos de João C. Tedesco e de Maria I. Paulilo como sendo os mais adequados para compreender a orientação tomada pelos agricultores, na busca de alternativas de reprodução social das famílias.

Registra-se, porém, que há dependência e subordinação econômica das unidades agrícolas, criadas pelo vínculo da produção integrada. E mais, pode também, o sistema integrado interferir internamente, diminuindo a produção de produtos paralelos ao fumo, mas sem eliminar aqueles considerados básicos para a unidade. Ademais, fica prejudicada a idéia aventada por alguns, da natureza capitalista da exploração agrícola integrada, uma vez que a razão do agricultor é menos empresarial e mais uma atitude estratégica de reprodução familiar.

Também se reconhece que a labuta no fumo demanda a ocupação intensiva do conjunto dos membros familiares, em pelo menos um terço do seu ciclo produtivo, o que pode diminuir as chances dos grupos domésticos, no sentido de empreenderem outras atividades comerciais no meio rural, principalmente aqueles que se localizam distantes dos centros consumidores, onde os aspectos infra-estruturais e institucionais são considerados cruciais para o desenvolvimento dessas novas iniciativas. Essa situação se reforça mediante o trabalho ideológico desempenhado pelos atore ${ }^{14} \mathrm{do}$ conglomerado transnacional fumageiro, que procuram reforçar a noção de que o fumo é a atividade agrícola mais rentável de que se tem conhecimento, se contrastado com os demais cultivos (como milho e feijão),

14 Fazem referência as representações do setor, no caso, o SINDIFUMO (Sindicato da Indústria do Fumo) e a AFUBRA. 
enfatizando, ainda, que se trata de uma atividade estável porque beneficiada com uma política de definição de preços e com a garantia de venda. Enquanto persistirem as condições atuais no mercado internacional para o produto (o país exporta mais de $80 \%$ do volume total produzido), o setor e as redes ligados ao tabaco continuarão promovendo-o. Diante deste quadro, vêem-se desestimuladas outras iniciativas inovadoras e geradoras de renda. Para Etges (2001), o meio rural da região tradicional produtora de fumo rio-grandense encontra-se apático e passivo ante o peso do padrão hegemônico da cadeia fumícola. O agricultor recebe um modelo de produção pronto, que não requer sua participação e que, muitas vezes, não leva em consideração a situação ambiental, social e econômica de muitas regiões, observa a autora.

O cultivo do fumo, com todas as suas implicações socioeconômicas, técnico-ambientais e culturais, insere a agricultura familiar de vários municípios sul-brasileiros num contexto global, guiado por grandes interesses econômicos. Especificamente, no espaço regional de Santa Cruz, berço da fumicultura rio-grandense, considerado por muitos (Fochezatto, 2002; Stülp, 2001; Spies, 1997) pouco diversificado, há lugar para se encetarem novas alternativas econômicas, sob outras bases tecnológicas em transição.

Mesmo neste ambiente no qual está enraizada a produção de tabaco em moldes convencionais, entendemos que os grupos de agricultores da região, membros da ECOVALE (Cooperativa Regional de Agricultores Familiares Ecologistas do Vale do Rio Pardo) hoje desenvolvendo atividades produtivas, sintonizados com os pressupostos da sustentabilidade na agricultura, estão redefinindo suas estratégias fora da fumicultura, com o fito de aumentar ou complementar a renda, a partir do comércio de produtos diferenciados.

Este movimento de defesa e de articulação dentro do sistema (a maioria continua fumicultor), mantêm os produtores atuando no jogo do 
mercado de troca, ora mais, ora menos, no compasso das estratégias tomadas ou decididas pelos agentes.

As estratégias adotadas seriam mecanismos de resistência à dominação capitalista do sistema ? Ou será que os agricultores estão apenas ocupando o espaço gerado pelo próprio modo contraditório das forças produtivas do capitalismo ? Graziano da Silva (1999) considera que uma proposta de longo prazo, de adequação tecnológica ou de emprego de tecnologias alternativas, como "estratégia de resistência" à dominação capitalista é um "furo n' água" que leva os agricultores à proletarização, isto é, à impossibilidade de reprodução material da família, num determinado nível social. Ele afirma ser mais adequado a "produção de consciência" social, para que se possa gerar novas formas ideológicas, no nível das relações sociais entre os próprios homens e entre os homens e natureza. A curto prazo, Graziano da Silva (1999) propõe a adoção de práticas conservacionistas e a indução de novas trajetórias científicas não-poluidoras da natureza.

\section{Comentários finais}

Nem mesmo o desenvolvimento do progresso técnico de ponta exigido na reprodução capitalista foi capaz de suplantar (ou proletarizar) a formação familiar de agricultura, como alguns profetizaram. Este processo motiva inclusive os agricultores de hoje a redefinirem suas estratégias de reprodução social da família e econômica da unidade, incorporando à produção interna dinamismo e flexibilidade, com a ajuda dos meios de que eles dispõem, como o trabalho doméstico, o assalariamento (quando requisitado) e a propriedade da terra.

Em face disso, e lembrando Lamarche (1993), a posição da agricultura familiar na contemporaneidade encontra-se em situações extremamente variadas e diferentes, pois, trata-se de uma formação social heterogênea. 
Isto requer, conforme Neves (1995), compreender as intercessões entre unidade familiar e unidade de produção, em meio a princípios diversos de organização do trabalho e da produção, isto é, trata-se de compreender os objetivos sociais (os projetos) que orientam as práticas dos agentes da família rural.

Na produção fumícola, tema centro da discussão precedente, o produto social do trabalho agrícola desempenhado pelos membros da família, revela-se uma prática não-capitalista. Ademais, nesse ramo de agricultura, nem o avanço tecnológico nem a defesa da especialização da produção aventada por alguns, levam à inevitabilidade do processo de proletarização dos agricultores fumeiros.

O início de um processo de seleção de grupos, mais adequado à produção de fumo, pode acontecer se houver uma decrescente demanda pelo produto, ao nível do comércio exterior, ou internamente através de medidas institucionais restritivas, encarecendo o crédito agrícola, por exemplo. Enquanto existir fluxo mercadológico desta matéria-prima, os agricultores continuarão sendo requisitados e subordinados ao capital agroindustrial, ainda que sem a expropriação de seus meios de produção.

Recorremos à expressão martiniana para defender nosso postulado de que os ganhos do agricultor são regulados pelo seu trabalho e o trabalho de sua família, não são ganhos de capital, (...) exatamente porque esses ganhos não provêm da exploração de um capitalista sobre um trabalhador expropriado dos instrumentos de trabalho (Martins, 1982, p. 59).

Com relação à evolução sócio-histórica da região referenciada, assinalamos a nascente de imensos desafios à promoção de práticas e de critérios de agricultura sustentável. Ao mesmo tempo, crê-se no processo de transição, se houver efetivamente uma atitude científica voltada à sustentabilidade ecológica, reivindicando em paralelo, políticas institucionais que promovam o desenvolvimento com qualidade de vida dos sujeitos do meio rural. 
Que desenho futuro de agricultura pode-se esperar na região? As novas iniciativas que surgem em agricultura sustentável vão vingar, estendendo-se aos agricultores adeptos de um novo formato tecnológico ? Ou será um nicho de produção e comércio somente para algumas famílias? O que se sabe, porém, é que as novas estratégias produtivas não podem ser dissociadas de compromissos públicos, da esfera municipal, estadual e federal.

À medida que avançamos nossos estudos acerca do objeto "fumicultura", prosseguimos na discussão em nível de doutoramento, elegendo o tema da transição agroambiental levado a cabo por alguns agricultores da região-berço da fumicultura rio-grandense. Sobre o tema eleito já nos temos debruçado, através de alguns ensaios teóricos e metodológicos apresentados em seminários, congressos, artigos publicados em periódicos e na recente obra co-organizada, denominada "Políticas para o desenvolvimento rural: sustentabilidade, cidadania e participação". No momento, seguimos aprofundando o arcabouço teórico dessa temática, cada vez mais complexa na contemporaneidade, com vistas a contribuir à efetiva opção dos fumicultores pela agricultura sustentável.

\section{Referências}

ABRAMOVAY, Ricardo. Agricultura familiar e uso do solo. São Paulo em perspectiva - SEADE. São Paulo, v. 11, n. 2, p. 73 - 78, 1997.

ABRAMOVAY, Ricardo. Paradigmas do capitalismo agrário em questão. 2. ed. São Paulo/Campinas: Hucitec/Unicamp, 1998, 275 p.

AFUBRA (Associação dos Fumicultores do Brasil). Perfil do fumicultor. Disponível em: http://www. afubra.com.br. Acesso em: 13 mar. 2004.

ARON, Raymond. Max Weber. In: . As etapas do pensamento sociológico. Tradução de Sérgio Bath. 6. ed. São Paulo: Martins Fontes, 2003, p. 725 - 838 (Coleção tópicos). 
CARRARO, André, BASSAN, Dilani S., SOUZA, Nali de Jesus de. Indicadores de desenvolvimento da região do Vale do Rio Pardo. In: SOUZA, Nali de Jesus de (Coord.) Evolução econômica e social da região do Vale do Rio Pardo. Santa Cruz do Sul: EDUNISC, 2002, p. 121 - 154.

CHAYANOV, Alexander, V. La organización de la unidad económica campesina. Buenos Aires: Nueva Visión, 1974, p. 09 - 131.

COREDE - VRP (Conselho Regional de Desenvolvimento do Vale do Rio Pardo). Agenda 21 Regional do Vale do Rio Pardo (RS). Santa Cruz do Sul: COREDE - VRP / FAPERGS, 2003 (mimio).

CRÉDITO RURAL DO PRONAF: Ministério do Desenvolvimento Agrário. Disponível em: http://www.pronaf.gov.br/credito/consulta. Acesso em: 23 ago. 2002.

CUNHA, Jorge L. da. Os colonos alemães e a fumicultura: Santa Cruz do Sul, Rio Grande do Sul 1849 - 1881. Santa Cruz do Sul: Ed. da FISC, 1991. 184p.

ECOVALE (Cooperativa Regional de Agricultores Familiares Ecologistas do Vale do Rio Pardo). A solidariedade fez nascer... Santa Cruz do Sul: ECOVALE/CAPA, 2002. (folder).

ETGES, Virgínia E. (Coord). Estudo para o desenvolvimento sustentável da agricultura familiar nas regiões do centro oeste e noroeste do Rio Grande do Sul. Relatório Técnico. Santa Cruz do Sul: UNISC - FAPERGS, 2001, 74 f. (mimio).

ETGES, Virgínia E. Sujeição e resistência: os camponeses gaúchos e a indústria do fumo. Santa Cruz do Sul: FISC, 1991. 209 p.

FOCHEZATTO, Adelar. Evolução da estrutura produtiva da região do Vale do Rio Pardo, 1986 / 1998. In: SOUZA, Nali de Jesus de (Coord) Evolução econômica e social da região do vale do Rio Pardo. Santa Cruz do Sul: EDUNISC, 2002, p. 87 120 .

GIDDENS., Anthony. Sociologia. Madrid: Aliança editorial, 1995, p. 743 - 769.

GRAZIANO DA SILVA, José. Tecnologia e agricultura familiar. Porto Alegre: Ed. da Universidade - UFRGS, 1999. 238 p.

GRAZIANO DA SILVA, José. A nova dinâmica da agricultura brasileira. Campinas: UNICAMP/IE, 1996, p. 01 - 40. 
GRAZIANO DA SILVA, José. A pequena produção e as transformações da agricultura brasileira. In: . A modernização dolorosa: estrutura agrária, fronteira agrícola e trabalhadores rurais no Brasil. Rio de Janeiro: Zahar, 1982, p. 126 - 141.

JEAN, Bruno. A forma social da agricultura familiar contemporânea: sobrevivência ou criação da economia moderna. Cadernos de Sociologia - Programa de PósGraduação em Sociologia - PPGS/UFRGS. Porto Alegre, v. 6, p. 51 - 75, 1994.

HERVIEU, Bertrand. Los campos del futuro. Madrid: Ministerio de Agricultura, Pesca y Alimentación, 1996, p. 24 - 109.

LAMARCHE, Hughes (Coord.). A agricultura familiar: comparação internacional. Tradução de Ângela Maria Naoko Tijiwa. Campinas: Ed. da UNICAMP, 1993, p. $11-33$.

LIEDKE. Elida R. Capitalismo e camponeses: relações entre indústria e agricultura na produção de fumo no Rio Grande do Sul. 1977. 130 f. Dissertação (Departamento de Ciências Sociais do Instituto de Ciências Humanas da Universidade de Brasília) - Universidade de Brasília, Brasília. 1977.

LIMA, Ronaldo G. de. Práticas alternativas e convencionais na cultura de fumo estufa: estudo de casos. 2000. 388 f. Dissertação (Programa de Pós-Graduação em Desenvolvimento Regional - Mestrado) - Universidade de Santa Cruz do Sul, Santa Cruz do Sul. 2000.

MARTINS, José de S. A sociedade vista do abismo: novos estudos sobre exclusão, pobreza e classes sociais. Petrópolis: Vozes, 2002. p. 49 - 117.

MARTINS, José de S. Expropriação \& violência: a questão política no campo. 2. ed. São Paulo: Hucitec, 1982, p. 45 - 66; 95 - 106.

MONTALI. Lilia T. Do núcleo colonial ao capitalismo monopolista: produção de fumo em Santa Cruz do Sul. 1979. 167 f. Dissertação (Faculdade de Filosofia, Letras e Ciências Humanas) - Universidade de São Paulo, São Paulo. 1979.

MÜLLER, Igor. A maior safra: colheita recorde consolida o Brasil como segundo maior produtor mundial. Jornal Gazeta do Sul, Santa Cruz do Sul, 14 e 15 fev. 2004. Gazeta Rural, p. 03.

MÜLLER, Igor. Região iniciará novo ano com 60 \% da safra colhida. Jornal Gazeta do Sul, Santa Cruz do Sul, 31 dez. 2003. Rural, p. 09. 
NEVES, Delma P. Agricultura familiar: questões metodológicas. Revista da Associação Brasileira da Reforma Agrária. Campinas, v. 24, n. 2 e 3, p. 21 - 36, mai./dez. 1995.

PAYÉS, Manoel A. M., SILVEIRA, Miguel A. da. A racionalidade econômica do empresário familiar. Jaguariúna: EMBRAPA/CNPMA, 1997. 21 p. (Documentos n. 10).

Paulilo, Maria Ignez S. Produtor e agroindústria: consensos e dissensos. Florianópolis: Ed. da UFSC - SECE, 1990. 184 p.

SACCO DOS ANJOS, Flávio. Agricultura familiar, pluriatividades e desenvolvimento rural no sul do Brasil. Pelotas: EGUFPel, 2003, p. 09 - 43.

SECEX/MDIC (Secretaria de Comércio Exterior/Ministério do Desenvolvimento, Indústria e Comércio Exterior). Resultados da balança comercial do agronegócio brasileiro - 2004. Disponível em : http://www.agricultura.gov.br/pls/portal/docs. Acesso em: 25 abr. 2005.

SOUZA CRUZ: a maior usina de beneficiamento de fumo do mundo. Jornal Gazeta do Sul, Santa Cruz do Sul, 12 dez. 1996. Encarte especial, 79 p.

SPIES, Rosalice S. O impacto de uma variação na demanda regional final sobre a economia do Vale do Rio Pardo - RS. Estudos do CEPE - Revista do departamento de ciências econômicas da UNISC, Santa Cruz do Sul, n. 5, p. 95 - 115, jan./jun. 1997.

STÜLP, Valter J. O setor primário da região do Vale do Rio Pardo. In: VOGT, Olgário P.;

SILVEIRA, Rogério L. L. da (Org.) Vale do Rio Pardo: (re)conhecendo a região. Santa Cruz do Sul: EDUNISC, 2001, p. 167 - 215.

TEDESCO, João C. A relatividade conceitual e os paradigmas da pequena produção familiar no pensamento sócio-econômico. Revista Teoria e Evidência Econômica - UPF, Passo Fundo, n. 4, p. 95 - 122, nov. 1994.

TEDESCO, João C. Contratualização e racionalidade familiar. In: (Org.) Agricultura familiar: realidades e perspectiva. 3. ed. Passo Fundo: UPF, 2001, p. 107 - 148. 
TESCHE, Otto, STÜLP, Jacson M., SILVA, Simone. Guia socioeconômico do Vale do Rio Pardo e Centro-Serra. Jornal Gazeta do Sul, Santa Cruz do Sul, 27 jun. 2003, p. 90 - 91.

VOGT. Olgário P. A produção de fumo em Santa Cruz do Sul, RS : 1849 - 1993. Santa Cruz do Sul: EDUNISC, 1997. 283 p.

WANDERLEY, Maria de Nazareth B. Raízes históricas do campesinato brasileiro. In: TEDESCO, João C. (Org.) Agricultura familiar: realidades e perspectivas. 3. ed. Passo Fundo: UPF, 2001, p. 21 - 55.

WANDERLEY, Maria de Nazareth B. O camponês: um trabalhador para o capital. Cadernos de Difusão de Tecnologia - Publicação do Departamento de Difusão de Tecnologia da EMBRAPA, Brasília, v. 2, n. 1, p. 13 - 78, jan./abr. 1985.

WEBER, Max. Economia e sociedade: fundamentos da sociologia compreensiva. Tradução de Regis Barbosa e Karen Elsabe Barbosa. Brasília: Ed. da UnB, 1991, p. $03-138 ; 229-239$.

\section{Resumo}

Discutimos neste texto a origem, a estruturação econômica e as relações sociais de trabalho no ramo da fumicultura. Entre as distintas visões teóricas sobre a temática da agricultura familiar, em particular a da economia fumícola, elegemos a noção weberiana de gestão patrimonial, a fim de compreender as atuais estratégias dos agricultores. Colocamos em discussão que, diferentemente da razão empresarial voltada ao lucro aquisitivo, o agricultor familiar em foco orienta suas estratégias de reprodução sem o cálculo capitalista. Ao final, comentamos a inconsistente defesa que aponta a inevitável proletarização dos agricultores fumeiros.

Palavras-chave: fumicultura, histórico, trabalho, relações de produção, sociologia rural.

Recebido: 20/12/2005

Aceite final: 01/06/06 